\title{
The relationship between frailty, functional dependence, and healthcare needs among community-dwelling people with moderate to severe dementia
}

\author{
Wilson Abreu' (D) | Debbie Tolson ${ }^{2}$ (D) | Graham A. Jackson² | Harry Staines ${ }^{3}$ | \\ Nilza Costa ${ }^{4}$
}

${ }^{1}$ Porto School of Nursing/CINTESIS (Center for Research in Health Technologies and Services), Porto, Portugal

${ }^{2}$ Alzheimer Scotland Centre for Policy and Practice, The University of the West of Scotland, Hamilton, UK

${ }^{3}$ The University of the West of Scotland, Hamilton, UK

${ }^{4}$ University of Aveiro - Campus Universitário de Santiago, Aveiro, Portugal

Correspondence

Wilson Abreu, Porto School of Nursing/ CINTESIS, Porto, Portugal.

Email:wjabreu@esenf.pt

\begin{abstract}
This paper examines the healthcare needs of community-dwelling older people living in Porto, Portugal, diagnosed with moderate or severe dementia, linked to functional dependency, cognitive decline, limitations in the activities of daily life, and frailty levels. A sample of 83 participants was recruited. Data were collected between 2013 and 2017. A sociodemographic questionnaire, the Clinical Dementia Rating (CDR), the Barthel Index (BI), the Lawton and Brody Instrumental Activities of Daily Living (IADL) Scale, and the Edmonton Frail Scale (EFS) were used. A set of 26 healthcare needs was defined to support the assessment. The Pearson chi-square or Fisher's exact test (as appropriate) was used to examine the association of the needs (unmet and met) with the levels of dementia and frailty. Participants were diagnosed previously with moderate or severe dementia and benefited from a structured home-care program. There was a high number rated as "severe dementia," "fully dependent," "severely or fully dependent in the activities of daily living (ADL)," and "severe frailty." There were statistically significant differences among needs identified in people with moderate or severe dementia and moderate or severe frailty. The most prevalent healthcare needs in the sample were food preparation, medication/taking pills, looking after their home, toilet use, sensory problems, communication/interaction, bladder, bowels, eating and drinking, memory, sleeping, and falls prevention. In particular, the study identifies a set of needs that are present simultaneously in both frailty and dementia stages. This study underlines that despite well-structured home-care programs for people with dementia, unmet health needs remain. Timely healthcare needs assessment may help professionals to avoid fragmented care and to tailor quality-integrated interventions, including the emotional and psychological balance of the caregiver.
\end{abstract}

\section{KEYWORDS}

activities of daily living, dementia, family caregiving, frailty, functional dependence, health needs assessment 


\section{1 | INTRODUCTION}

The increasing longevity and the progressive dependence of people with dementia is a worldwide concern (Prince et al. 2015; Winblad et al., 2016). The number of people currently living with dementia is estimated as 47.7 million and is expected to reach 75.63 million by 2030 and 135.46 million by 2050 (WHO, 2015). Dementia is a term for a clinical syndrome characterised by progressive acquired global impairment of cognitive skills and ability to function independently (Sheeman, 2012).

From an early stage, people with dementia need progressively more support to continue their activities of daily living (ADL) and their own safety and integrity (Muders, Zahrt-Omar, Bussmann, Haberstroh, \& Weber, 2015). This loss of functional capacity is accompanied by reduced capacity to perform instrumental activities of daily living (IADL) and by an increasing frailty (Abreu, Rodrigues, Sequeira, Pires, \& Sanhudo, 2017).

Frailty is associated with dementia when a high level of cognitive declines is present; this explains the importance of adjusting for baseline cognition in studies examining the association between frailty and dementia outcomes (Gray et al., 2013). There is evidence to support the notion that frailty may precede dementia (Boyle, Buchman, Wilson, Leurgans, \& Bennett, 2010) and also for the notion that mild dementia may precede the development of frailty (Raji, Snih, Ostir, Markides, \& Ottenbacher, 2010).

Frailty is described as one of the most challenging expressions of ageing that decreases the quality of life and independence of older adults in the self-care and in the ADL (Clegg, Young, lliffe, Rikkert, \& Rockwood, 2016). Older frail people also experience dramatic decline in physical and mental functions and have poorer outcomes after even apparently minor stressors such as mild physical disorders and anxiety, as shown in several studies (Pialoux, Goyard, \& Lesourd, 2012).

There is no standard definition for frailty (Rodríguez-Mañas et al., 2012), but generally accepted components include muscle weakness, fatigue, slowness, low physical activity, and unintended weight loss (Fried et al., 2001; Kalyani, Varadhan, Weiss, Fried, \& Cappola, 2012). "Frail" does not mean comorbidity or disability, so this term cannot be chosen to describe older people in general (Walston et al., 2006).

The increase in dementia prevalence calls for new interventions, involving social and political decision-makers (Burla, Rego, \& Nunes, 2014). There is a consensus on the need to provide more compassionate and higher quality care to people with dementia and to avoid unnecessary hospital admissions.

The incidence and prevalence of dementia are strongly age dependent (Sheeman, 2012). Many people show varying levels of behaviour disturbance, dependence, and frailty at some point in the dementia syndrome, and evidence is growing that some of the health needs of the person are related to comorbidities and later life conditions, rather than the dementia itself (Crowther, 2015). Care provision from health professionals and family members increases as the condition progresses, however not all needs are consistently met (Van derPloeg, Bax, Boorsma, Nijpels, \& VanHout, 2013).

\section{What is known about this topic}

- Evidence has shown that the quality of dementia care is often suboptimal after diagnosis;

- A comprehensive assessment of the healthcare needs is indispensable to decisions related to the provision of care;

- Avoiding hospital stays in older people leads to a reduction in hospital-acquired infection and premature death.

\section{What this paper adds}

- This is one of the first studies providing a detailed examination of the level of needs of people with moderate to severe dementia with particular reference to functional dependency instrumental activities of daily living (IADL) and frailty;

- Timely healthcare needs assessment helps professionals to avoid fragmented care and to tailor quality-integrated interventions including the emotional and psychological balance of the caregiver.

Need can be defined for our purposes as a state where help (or more help) with specific difficulties is seen to be required by the care professional making the assessment, taking into account the views of the person assessed (or their advocate) (McWalter et al., 1994). The relationship between met and unmet needs and quality of life is commonly accepted; unmet needs can be divided into subjective, objective, personal, and societal needs (ScholzelDorenbos, Meeuwsen, \& Olde Rikkert, 2010). Subjective needs are those experienced by the person and their caregivers, for example, the need for comfort and compassion; however, objective needs are objectively diagnosed needs, for example, in patients with clear signs of neglect.

Late stage dementia can also be called "advanced dementia" (Aminoff, 2014; Tolson et al, 2017), "severe dementia" (Sampson, 2010), or "end stage of dementia" (Potter, Fernando, \& Humpel, 2013). The care provided in the later stages of dementia is often fragmented and people may die because of unrecognised and untreated symptoms and needs, thereby experiencing considerable apathy and suffering (Jones et al., 2016). The strong association between apathy and people's abilities to complete basic ADL is evident in this phase. The assessment of needs and dependence in perform ADL must be comprehensive and include not only physical but also social and psychological functioning (Miranda-Castillo et al., 2010).

A health needs assessment is a staged process (Cavanagh \& Chadwick, 2005), conducted by a care professional, which begins with the identification of specific difficulties, accounts for the presence and efficacy of current help, recognises perceived need, and finally specifies the type of intervention required to meet those needs (Meaney, Croke, \& Kirby, 2005). 
Health needs assessments are a key health strategy, which should be used; (a) to provide evidence about a population on which to plan services and address health inequalities, (b) provide an opportunity to engage with specific populations and enable them to contribute to targeted service planning and resource allocation, and (c) provide an opportunity for cross-sectoral partnership working and developing creative and effective interventions. Health needs assessments are important activities to promote rationalisation of resources in the integrated continuous care networks (Brewin, 2001; Koike \& Furui, 2013).

This paper examines the healthcare needs of community-dwelling older people living in Porto, Portugal, diagnosed with moderate or severe dementia. Specific objectives are:

1. to assess the functional dependency and the living skills of the persons with moderate and severe dementia;

2. to identify the unmet needs of the persons with moderate and severe dementia;

3. to investigate whether unmet needs are linked to frailty levels.

\section{MATERIALS AND METHODS}

This study is part of a larger project (DRIVE-C) focused on caring for people with dementia at home, in the Porto District of North Portugal (https://www.esenf.pt/pt/i-d/projetos-internacionais/ drive-c/). The study was completed over 3 years (2014-2017). The findings related to family caregivers are presented elsewhere (Abreu, Tolson, Jackson, \& Costa, 2018).

\section{1 | Settings and participants}

A cross-sectional survey design was undertaken with dementia caregivers and/or individuals with dementia who were invited to complete a multicomponent battery of tools. Eighty-three persons with moderate or severe dementia living in Porto, along with their family caregivers, were recruited. The recruitment strategy was negotiated with the healthcare team, according to the clinical situation of the recipients of care and motivation to cooperate in the study. Visits were scheduled according to the caregivers' availability.

Inclusion criteria for this study were: (a) persons diagnosed with moderate or severe dementia by a physician using the Clinical Dementia Rating (CDR); (b) having an initial clinical assessment performed by the multidisciplinary team; and (c) having the support of the local Integrated Community Care Team that provides long-term care.

\subsection{Data collection}

The following instruments were used in the study: a sociodemographic questionnaire, the Barthel Index (BI), the Lawton and Brody IADL Scale, and the Edmonton Frail Scale (EFS).

The sociodemographic questionnaire was used to collect data from the person with dementia, the caregiver, and the context of care.
The BI (Mahoney \& Barthel, 1965) is widely used in clinical practice and research to assess the degree of dependence (functional status) in ADL, with scores from 0 (high dependence) to 100 (high independence). This index is used to assess the functional capacity of the person and to determine the level of dependence overall and for each activity. The BI was validated for the Portuguese population by Araújo, Pais Ribeiro, Oliveira, Pinto, and Martins (2007). The Portuguese version shows very good psychometric properties (Cronbach Alpha $=0.96$ ) and interitem correlations $(r)$ between 0.66 and 0.93 (Araújo et al., 2007).

The IADL Scale is an appropriate instrument to assess independent living skills (Lawton \& Brody, 1969). The scale assesses eight tasks (the ability to use the telephone, shop, prepare food, handle finances, do housework, take medication, do laundry and travel) related to functional skills necessary to live independently in the community. Each activity is scored from 1 to 3 or 1 to 4 , depending the activity with a higher score associated with greater ability. Some of the reasons behind its widespread use are its easy application and interpretation, low cost, it does not require specialised personnel for its application, and takes a short time to complete (Araújo, Pais Ribeiro, Oliveira, Pinto, \& Martins, 2008).

The EFS assesses nine domains of frailty (cognition, general health status, functional independence, social support, medication usage, nutrition, mood, continence, and functional performance) in older people (Rolfson, Majumdar, Tsuyuki, Tahir, \& Rockwood, 2006). The total score ranges from 0 to 17 with higher scores representing greater levels of frailty. Severe frail and non-frail participants were defined according of the EFS score from not frail (0-5); vulnerable (6-7); mild frailty (8-9); moderate frailty (10-11); and severe frailty (12-17). The scale was validated in 2012 for the Portuguese population by Martins, Carvalho, Cordeiro, and Pinheira (2012) showing good psychometric properties. Martins et al (2012) calculated the reference values for the Portuguese average population. It had a value of 0.97 for Cronbach's alpha and a reliability threshold of 0.94 for test-retest reliability ( $95 \%$ confidence interval, 0.90-0.96).

The CDR, developed by Hughes, Berg, Danziger, Coben, and Martin (1982), is a numeric scale commonly used by psychogeriatric ward staff to quantify the severity of symptoms of dementia. The Portuguese version was validated by Garret et al. (2008).

The health needs assessment was developed based on the Care Needs Assessment Pack for Dementia (CarenapD-McWalter et al., 1998).The CarenapD tool is used worldwide in needs assessment. We had to choose which tool or strategy gave the most robust opportunity to measure the needs of the people who we are trying to assess. As the assessment was integrated in the period of care delivery, our option was to use a set of needs that were documented in the clinical records, which facilitated the provision of continuumbased dementia care that better meets the individual needs of persons with dementia. A set of needs was added to the traditional list: interaction, breathing, cutaneous integrity, mood, memory, confusion, usual sleep, emotional management, recognising familiar people, and make decisions and plans. 
TABLE 1 Sociodemographic characteristics of the person with dementia and the family caregivers $(N=83)$

\begin{tabular}{|c|c|c|}
\hline Variables & $\begin{array}{l}\text { Person with dementia } \\
(n=83)\end{array}$ & $\begin{array}{l}\text { Family caregiver } \\
(n=83)\end{array}$ \\
\hline Age (mean) & $\begin{array}{l}79.95 \text { (Range 50-95) } \\
\text { (SD: } 7.46)\end{array}$ & $\begin{array}{l}60.64 \text { (Range } \\
25-87)(\text { SD: 13.74) }\end{array}$ \\
\hline \multicolumn{3}{|l|}{ Gender } \\
\hline Male & $28(33.7 \%)$ & $11(13.3 \%)$ \\
\hline Female & $55(66.3 \%)$ & $72(86.7 \%)$ \\
\hline \multicolumn{3}{|l|}{ Education level } \\
\hline $\begin{array}{l}\text { Less than } \\
\text { primary school }\end{array}$ & 15 (18.1\%) & $4(4.8 \%)$ \\
\hline $\begin{array}{l}\text { Completed } \\
\text { primary school }\end{array}$ & $66(79.5 \%)$ & $63(75.9 \%)$ \\
\hline $\begin{array}{l}\text { Completed } \\
\text { secondary } \\
\text { school }\end{array}$ & $1(1.2 \%)$ & $9(10.8 \%)$ \\
\hline $\begin{array}{l}\text { Bachelor degree } \\
\text { or more }\end{array}$ & $1(1.2 \%)$ & $7(8.4 \%)$ \\
\hline \multicolumn{3}{|c|}{ Employment/occupation } \\
\hline Employed & & $20(24.1 \%)$ \\
\hline Retired (age) & & $18(21.7 \%)$ \\
\hline Unemployed & & $15(18.1 \%)$ \\
\hline $\begin{array}{l}\text { Retired } \\
\text { (disability) }\end{array}$ & & 15 (18.1\%) \\
\hline Domestic work & & $12(14.5)$ \\
\hline Other & & $2(2.4 \%)$ \\
\hline Student & & $1(1.2 \%)$ \\
\hline \multicolumn{3}{|c|}{ Relationship of family caregiver with the person with dementia } \\
\hline Wife/husband & & $30(36.1 \%)$ \\
\hline Son/daughter & & 30 (36.1\%) \\
\hline Father/mother & & $7(8.4 \%)$ \\
\hline Other & & $7(8.4 \%)$ \\
\hline $\begin{array}{l}\text { Son-in-law/ } \\
\text { daughter-in-law }\end{array}$ & & $4(4.8 \%)$ \\
\hline Brother/sister & & $3(3.6 \%)$ \\
\hline $\begin{array}{l}\text { Grandson/ } \\
\text { granddaughter }\end{array}$ & & $2(2.4 \%)$ \\
\hline \multicolumn{3}{|c|}{ Time of caregiving (months) } \\
\hline Less than 6 & & $23(27.7 \%)$ \\
\hline $6-11$ & & $27(32.5 \%)$ \\
\hline $12-23$ & & $6(7.2 \%)$ \\
\hline $24-35$ & & $9(10.8 \%)$ \\
\hline $36-47$ & & $6(7.2 \%)$ \\
\hline 48 and more & & $12(14.5 \%)$ \\
\hline
\end{tabular}

The health needs assessment was reviewed systematically throughout the study, using two different raters (both mental health nurses) who work closely with the family caregivers and the recipients of care.

As data from the people with dementia were collected and rated by two researchers, establishing rigorous methods for assessing the reliability (consistency) and validity (accuracy) of data was important. There are not standard published methods for assessing interrater reliability. We decide to collect data from people who are continually cared for by the healthcare team. The researchers (raters) made their observations and discussed the results with the family nurse. To ensure accuracy, only the participants who have the same evaluation from the researchers were included in the study. For judgement items, the entries had to agree exactly-this was the requirement to transfer the values to the database. The two researchers concurred on all reviews of all items.

The final list that was adopted in this study includes 26 needs encompassing four domains of functioning that are specific and relevant to that individuals with dementia: environmental needs, physical needs, psychological needs, and social needs. The care need status indicated for each item is defined as unmet need or independent/no need.

\section{3 | Statistical analysis}

The data analysis was performed using SPSS version 24.0 (Statistical Package for the Social Sciences; SPSS Inc., Chicago, IL). The frequencies of needs (unmet and met) were compared between participants with moderate/severe dementia and moderate/severe frailty, using the Pearson chi-square test. If the contingency table included at least one cell with expected frequency less than five, then the Fisher's exact test was used. Univariate tests used an unadjusted $5 \%$ significance interval.

\subsection{Ethical considerations}

The study was approved by the human subjects' review boards (Institutional Review Board ULS-33/2014/RS) and was conducted in accordance with the principles of the Declaration of Helsinki (2013). Participants (persons with dementia) or the family caregivers provided consent to participate in the study. Participants were informed of the content and purpose of the study. Taking part in the research or otherwise did not interfere with any treatment or drug administration. Data anonymity, confidentiality, and the right to withdraw from the study at any time were guaranteed.

\section{3 | FINDINGS}

Table 1 summarises the sociodemographic characteristics of the study sample (persons with dementia and their caregivers). The sample comprised of 83 people formally diagnosed with moderate or severe dementia living in the community (mean age 75.95 years, range 50-95). The majority were women (66.3\%) and most had completed primary school (75.9\%). Caregivers were also mostly women $(86.7 \%)$ with a mean age of 60.64 years; $60.2 \%$ of caregivers had been caring for their relative for less than 12 months of caring. However, $14.5 \%$ had cared for their relative for at least 48 months. 


\begin{tabular}{|c|c|c|c|}
\hline \multirow[b]{3}{*}{ Person with dementia } & \multicolumn{3}{|c|}{ CDR (stage of dementia) } \\
\hline & \multirow{2}{*}{$\begin{array}{l}\text { Moderate }(n=30) \\
n(\%)\end{array}$} & \multirow{2}{*}{$\begin{array}{l}\text { Severe }(n=53) \\
n(\%)\end{array}$} & \multirow{2}{*}{$\frac{\text { Total }(n=83)}{n(\%)}$} \\
\hline & & & \\
\hline \multicolumn{4}{|l|}{ Types of dementia } \\
\hline Alzheimer's disease & $12(40.0 \%)$ & $21(39.6 \%)$ & $33(39.8 \%)$ \\
\hline Under assessment & $12(40.0 \%)$ & $15(28.3 \%)$ & $27(32.5 \%)$ \\
\hline Vascular dementia & $6(20.0 \%)$ & $4(7.5 \%)$ & $10(12 \%)$ \\
\hline Frontotemporal & 0 & $5(9.4 \%)$ & $5(6 \%)$ \\
\hline Mixed dementia & 0 & $59.4 \%)$ & $5(6 \%)$ \\
\hline Other & 0 & $2(3.7 \%)$ & $2(2.4 \%)$ \\
\hline $\begin{array}{l}\text { Dementia with Lewy } \\
\text { bodies }\end{array}$ & 0 & $1(1.8 \%)$ & $1(1.2 \%)$ \\
\hline Total & 30 (100.0\%) & 53 (100.0\%) & 83 (100.0\%) \\
\hline
\end{tabular}

TAB LE 2 Stage and types of dementia of the patients $(N=83)$

Note. CDR: Clinical Dementia Rating.

\begin{tabular}{|c|c|c|c|}
\hline \multirow[b]{2}{*}{ Instruments and categories } & \multicolumn{2}{|c|}{ Dementia stage (CDR) } & \multirow[b]{2}{*}{ Total $(n=83)$} \\
\hline & $\begin{array}{l}\text { Moderate } \\
(n=30)\end{array}$ & Severe $(n=53)$ & \\
\hline \multicolumn{4}{|l|}{ Barthel Index } \\
\hline Independent (>90-100) & 0 & 0 & 0 \\
\hline Slightly dependent (60-90) & $13(43.3 \%)$ & 0 & $13(15.7 \%)$ \\
\hline $\begin{array}{l}\text { Moderately dependent } \\
(40-55)\end{array}$ & $8(26.7 \%)$ & $8(15.0 \%)$ & $16(19.3 \%)$ \\
\hline Severely dependent (20-35) & $5(16.7 \%)$ & $7(13.3 \%)$ & $12(14.5 \%)$ \\
\hline Fully dependent $(<20)$ & $4(13.3 \%)$ & $38(71.7 \%)$ & $42(50.6 \%)$ \\
\hline Total & 30 (100\%) & 53 (100\%) & 83 (100\%) \\
\hline \multicolumn{4}{|l|}{ Lawton and Brody ADL } \\
\hline Independent & 0 & 0 & 0 \\
\hline Moderately dependent & 0 & 0 & 0 \\
\hline Severely or fully dependent & $30(100 \%)$ & $53(100 \%)$ & $83(100 \%)$ \\
\hline Total & $30(100 \%)$ & $53(100 \%)$ & $83(100 \%)$ \\
\hline \multicolumn{4}{|l|}{ EFS } \\
\hline Not frail $(0-5)$ & - & - & 0 \\
\hline Vulnerable (6-7) & & 0 & 0 \\
\hline Mild frailty (8-9) & & 0 & 0 \\
\hline Moderate frailty (10-11) & 25 (83.3\%) & $14(26.4 \%)$ & $36(0 \%)$ \\
\hline Severe frailty (12-17) & $5(16.7 \%)$ & 39 (73.6\%) & $44(0 \%)$ \\
\hline Total & $30(100 \%)$ & $53(100 \%)$ & $83(100 \%)$ \\
\hline
\end{tabular}

TABLE 3 Functionality, frailty, and dementia stages $(N=83)$

Note. ADL: Activities of Daily Living; BI: Barthel Index; CDR: Clinical Dementia Rating; EFS: Edmonton Frail Scale.

Table 2 shows the severity of disease and types of dementia of the sample participants. The diagnosis was made by a local physician during the first month and was stored in the person's clinical record, which is regularly updated through a multidisciplinary approach. The table emphasises the number of patients with severe dementia (63.9\%). By far the most common type of dementia is Alzheimer's disease (39.8\%), followed by vascular dementia (12.0\%), but there were also a high number of persons whose dementia diagnosis is still being assessed (32.5\%). Among the people with severe dementia (last CDR stage), 39.6\% were diagnosed with Alzheimer's disease.

Table 3 shows the functional decline and frailty of the participants, measured by the BI, IADL Scale, and EFS. The table 
compares results between persons who have moderate with those who have severe dementia. Classifying people with dementia according to their functional level (BI) demonstrates that there was a concentration in the "fully dependent" group (50.6\%). Individuals who are fully dependent and people and those who are severely dependent (14.5\%) need expert and sometime intensive support from their caregivers as they are unable to independently perform instrumental daily living activities.

The EFS assessed cognitive impairment, dependence for ADL, burden of illness, self-perceived health, depression, weight loss, medication issues, incontinence, social support, and mobility. After scoring the reported EFS, as shown in the Table 3, $44 \%$ of people with dementia had severe and $36 \%$ moderate frailty. Table 3 includes also a table to show the relation between frailty and the severity of dementia. As can be observed, $73.6 \%$ of those with severe dementia also have severe frailty. However, $16.7 \%$ of people with moderate dementia also have severe frailty.

Table 4 shows the relationship between the frailty level of the 83 persons with dementia and the 26 needs, classified as unmet or independent/no need. In general, people with severe frailty had higher rates of unmet needs. Of particular note is that all severely frail participants had unmet needs for food preparation, medication/taking

TAB LE 4 Chi-square test of independence for needs and frailty $(N=83)$

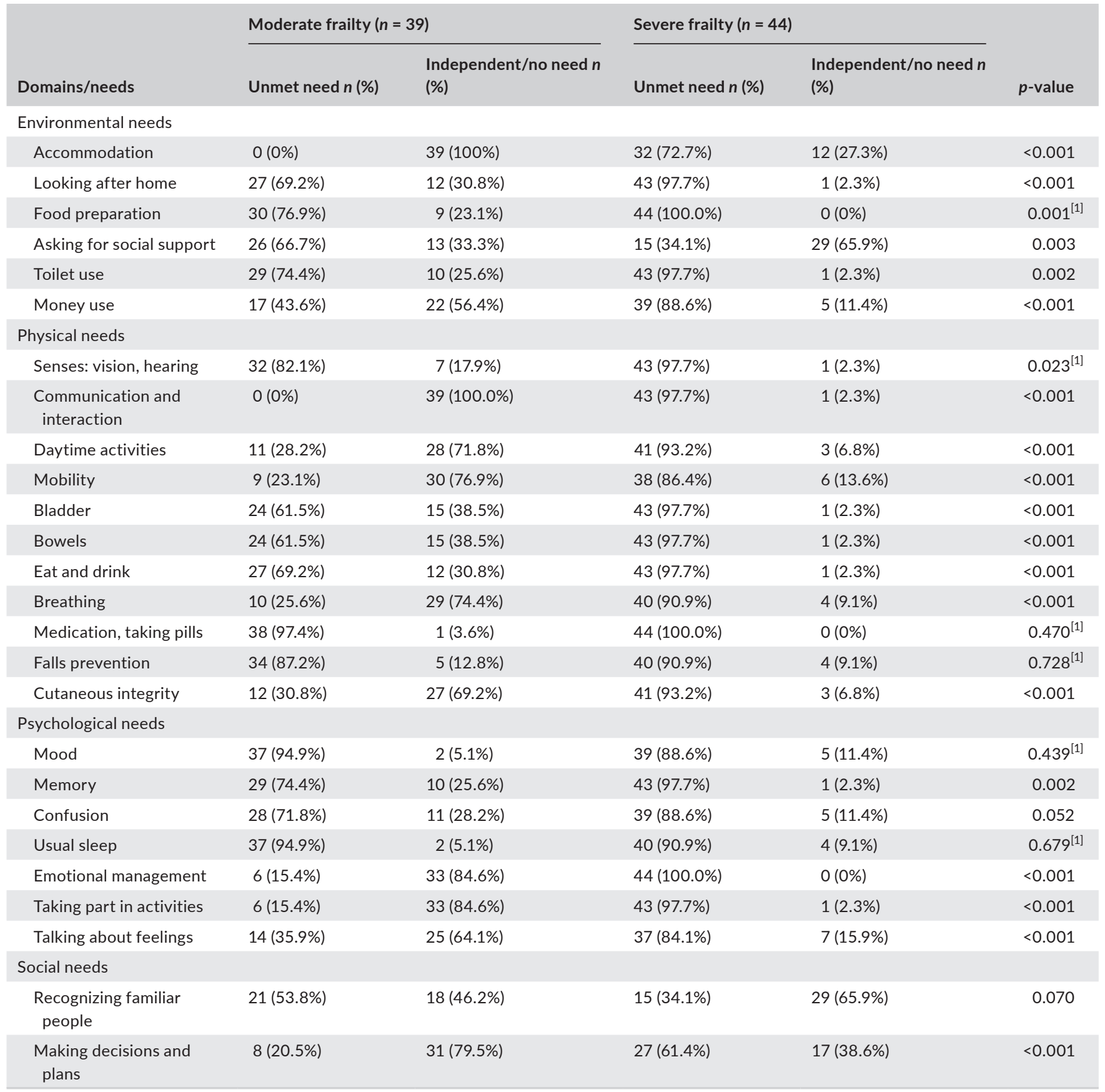

Note. Using chi-squared test except for ${ }^{[1]}$ which use Fisher's exact test. 
TAB LE 5 Chi-square test of independence for needs and stages of dementia $(N=83)$

\begin{tabular}{|c|c|c|c|c|c|}
\hline Domains/needs & \multicolumn{2}{|c|}{ Moderate dementia $(n=30)$} & \multicolumn{2}{|c|}{ Severe frailty $(n=53)$} & $p$-value \\
\hline \multicolumn{6}{|l|}{ Environmental needs } \\
\hline Accommodation & $5(16.7 \%)$ & $25(83.3 \%)$ & 27 (50.9\%) & $26(49.1 \%)$ & 0.002 \\
\hline Looking after home & $18(60,0 \%)$ & $12(40.0 \%)$ & 52 (98.1\%) & $1(1.9 \%)$ & $<0.001^{[1]}$ \\
\hline Asking for social support & $15(50.0 \%)$ & $15(50.0 \%)$ & $26(49.1 \%)$ & 27 (50.9\%) & 0.934 \\
\hline Toilet use & $20(66.7 \%)$ & $10(33.3 \%)$ & $52(98.1 \%)$ & $1(1.9 \%)$ & $<0.001^{[1]}$ \\
\hline Money use & $11(36.7 \%)$ & 19 (63.3\%) & 45 (84.9\%) & $8(15.1 \%)$ & $<0.001$ \\
\hline \multicolumn{6}{|l|}{ Physical needs } \\
\hline Daytime activities & $9(30.0 \%)$ & $21(70.0 \%)$ & $43(81.1 \%)$ & $10(18.9 \%)$ & $<0.001$ \\
\hline Mobility & 7 (23.3\%) & $23(76.7 \%)$ & $40(75.5 \%)$ & $13(24.5 \%)$ & $<0.001$ \\
\hline Bladder & $15(50.0 \%)$ & $15(50.0 \%)$ & 52 (98.1\%) & $1(1.9 \%)$ & $<0.001$ \\
\hline Bowels & $15(50.0 \%)$ & $15(50.0 \%)$ & 52 (98.1\%) & $1(1.9 \%)$ & $<0.001$ \\
\hline Eat and drink & $18(60,0 \%)$ & $12(40.0 \%)$ & 52 (98.1\%) & $1(1.9 \%)$ & $<0.001^{[1]}$ \\
\hline Breathing & 7 (23.3\%) & $23(76.7 \%)$ & $43(81.1 \%)$ & 10 (18.9\%) & $<0.001$ \\
\hline Medication, taking pills & $29(96.7 \%)$ & $1(3.3 \%)$ & 53 (100.0\%) & $0(0 \%)$ & $0.361^{[1]}$ \\
\hline Falls prevention & 25 (83.3\%) & $5(16.7 \%)$ & 49 (92.5\%) & $4(7.5 \%)$ & $0.273^{[1]}$ \\
\hline Cutaneous integrity & $9(30.0 \%)$ & $21(70.0 \%)$ & 44 (83.0\%) & 9 (17.0\%) & $<0.001$ \\
\hline Taking part in activities & $5(16.7 \%)$ & 25 (83.3\%) & 44 (83.0\%) & 9 (17.0\%) & $<0.001$ \\
\hline Talking about feelings & 3 (10.0\%) & 27 (90.0\%) & 48 (90.6\%) & $5(9.4 \%)$ & $<0.001$ \\
\hline \multicolumn{6}{|l|}{ Social needs } \\
\hline $\begin{array}{l}\text { Recognising familiar } \\
\text { people }\end{array}$ & $11(36.7 \%)$ & 19 (63.3\%) & $25(47.2 \%)$ & $28(52.8 \%)$ & 0.354 \\
\hline $\begin{array}{l}\text { Making decisions and } \\
\text { plans }\end{array}$ & $3(10.0 \%)$ & 27 (90.0\%) & 32 (60.4\%) & $21(39.6)$ & $<0.001$ \\
\hline
\end{tabular}

Note. Using chi-squared test except for ${ }^{[1]}$ which use Fisher's exact test.

pills, and emotional management, while $97.7 \%$ had unmet needs for looking after home, toilet use, senses, communication/interaction, bladder, bowels, eat and drink, memory, and taking part in activities. However, people with moderate frailty also showed high rates of unmet in some needs such as medication/taking pills (97.4\%), mood and sleep (94.9\%), falls (87.2\%), and senses (82,1\%).

The chi-square or Fisher's exact $p$ values are significant (unadjusted two-sided $p<0.05$ ) for 20 from the 26 needs, consistent with a statistically significant association between the variables (needs and level of frailty). Non-statistically significant $p$-values were found for medication/taking pills ( $p=0.470)$, falls prevention $(p=0.728$, mood $(p=0.439)$, confusion $(p=0.052)$, usual sleep $(p=0.679)$, and recognising familiar people $(p=0.070)$. For these, there was a relatively high unmet needs for participants with moderate frailty.

Table 5 shows the relationship between the dementia stage of the 83 persons and the 26 needs, classified also as unmet or independent/no need. From the table, we can observe that, in general, people with severe dementia have, as expected, higher rates of unmet needs. The following examples are prominent: food preparation, medication/taking pills (100\%), looking after home, toilet use, bladder, bowels, eat and drink, memory, senses and usual sleep (94.3\%), mood and falls prevention (92.5\%). People 
with moderate dementia also have unmet needs. Examples include medication/taking pills (96.7\%), mood and sleep (90.0\%), senses and falls (83.3\%).

Chi-square or Fisher's exact $p$ values (as appropriate) are significant $(p<0.05$ ) for 19 of the 26 needs, consistent with a statistically significant association between the variables (needs and stage of dementia). Non-statistically significant $p$-values were found for asking for social support ( $p=0.934)$, senses $(p=0.131)$, medication/taking pills ( $p=0.361$ ), falls prevention $(p=0.273)$, mood $(p=0.699)$, usual sleep $(p=0.663)$, and recognising familiar people $(p=0.354)$. Unmet needs can be found in both groups providing evidence that people with moderate dementia also show unmet needs.

\section{DISCUSSION}

The main purpose of this study was to examine the care needs of community-dwelling older people diagnosed with moderate or severe dementia. Specific objectives were to assess the functional dependence, living skills, and frailty and to identify met and unmet care needs.

The sociodemographic characteristics of our study participants with dementia and their caregivers are in line with those indicated in similar studies, namely, the mean age of the recipients of care and that from the caregivers. There is a concentration on "severe dementia."

The most common type of dementia in the sample is Alzheimer's disease. The proportion of people with Alzheimer's disease in this study is higher than others reported in similar researches carried out in Portugal (Nunes et al., 2010). There is a substantial number of people yet to have a specific diagnosis. Diagnosis of dementia is a complex medical and social practice; physicians search for robust evidence to make the diagnosis, which has still associated stigma and often cause emotional distress and anxiety (Dhedhi, Swinglehurst, \& Russell, 2014).

This study showed that there was a concentration of persons that are "fully dependent" (50.6\%). The study showed also that $44 \%$ of people with dementia had severe and $36 \%$ moderate frailty. Frailty is described as one of the most challenging expressions of ageing that decreases the quality of life and independence of older adults in the self-care and in the IADL (Clegg et al., 2016; Pialoux et al., 2012).

Our study found strong evidence that frailty among older people correlates with the advanced dementia stage and the capacity to perform the IADL, which is in itself a requirement to benefit from quality, competent, and compassionate care. When trying to calculate the relation between frailty and the severity of dementia, it can be observed that $73.6 \%$ of people with severe dementia have severe frailty too.

The assessment of functionality, IADL, and frailty demonstrates differences even between people with moderate and later stages of dementia. People may have complex physical and psychological symptoms in addition to the symptoms derived from cognitive decline due to comorbidities. In people with advanced dementia, timely cases of institutionalisation are accepted to deal with exacerbations (comorbidities) or to allow rest for caregivers. However, on a daily basis, comfort, interaction, proximity, and sensory interventions are essential, which require a biopsychosocial assessment instead of a neuropsychiatric one. Professionals should perform a full biopsychosocial assessment of assets, strengths, needs, and preferences of the person with dementia (Holmerova et al, 2016). One relevant finding in this study is the relativity of a symptom-based appraisal, rather than one based on real needs, related to memory, confusion, talking about feelings, meals (eat and drink), toilet, communication, elimination, mobility, mood and cutaneous integrity, among others.

Even when dementia is recognised in the primary care setting, research indicates that the quality of dementia care is suboptimal after diagnosis (Pimlott et al., 2009). Some of the needs in persons with dementia are frequently underestimated, for example, accommodation, breathing, falls prevention, cutaneous integrity, taking part in activities, talking about feelings, and making decisions and plans. Frequently, needs assessment separates the evaluation of different people (professionals, family caregiver, and person with dementia) (Callahan et al., 2006; Johansson, Eklund, \& Gosman-Hedstrom, 2010). The assessment of needs should be taken into account the past life experiences, cultural background, preferences, and identities (Holmerova et al, 2016) and joint together the recipient of needs, the caregivers, and the professionals (Dinand, Nover, Holle, Zischka, \& Halek, 2016).

It is recognised in this study that frailty should be seen as a multidimensional syndrome (Wou \& Conroy, 2013) affecting the physical and mental function of the persons in different ways. Cognitive (Buchman, Schneider, Leurgans, \& Bennett, 2008) and emotional impairment (Buchman et al, 2014) resulting from ageing had been frequently reported in the frail older people while many of the screening tools determine only physical deficits as a proxy measures of frailty (Heuberger, 2011).

Significant differences were found when trying to evaluate some needs from people with moderate and severe dementia. $P$ values were significant $(p<0.05)$ for 19 of the 26 needs, consistent with a statistically significant association between the variables (needs and stage of dementia). For the group with severe dementia, the most frequently identified needs were food preparation, medication/taking pills, looking after home, toilet use, senses, communication/interaction, bladder, bowels, eat and drink, memory, senses, usual sleep, and falls prevention. In those with moderate dementia, the most frequent care needs were medication/taking pills, mood and sleep, senses and falls. Globally, the pattern of needs show by people with severe dementia shows a decline in functionality and memory, but indicates a considerable capacity to interact and communicate, which facilitate ensuring a knowledge of individuals' opinions and preferences for decision-making. People with moderate dementia manifest some capacities that can contribute to their quality of life, delay memory, and physic decline (accommodation, asking for social support, communication, daytime activities, mobility, sphincter functioning, emotional management, taking part of activities, talking about feelings, recognising relatives, and making decisions and plans).

We found in this study that $16.7 \%$ of people with moderate dementia were also diagnosed with severe frailty. Concerning the 
needs assessment, the concept of "severe dementia" is clearly a limiter in matter of frailty. As an alternative, the expression of "advanced dementia," encompassing people with severe dementia and people with moderate dementia but who also have severe frailty, would be more consistent and facilitating optimal care delivery.

Findings show that the set of 26 needs used in this study was useful to sustain an appropriate understating of the health status of the recipient of care and support the assessment as a process, acknowledges changes over time. To know the preferences, talk about feelings, respect the identity, how to stay comfortable, respect requests for help or facilitating participation in simple activities can make a difference when caring for people with advanced dementia.

In line with previous studies (Miranda-Castillo Woods \& Orrell, 2013; Van der Ploeg et al., 2013; Van der Roest et al., 2007), our study showed a high number of healthcare needs, as described. Additionally, the study identifies a set of needs that are present simultaneously in frailty and advanced dementia stages. These are important findings to be taken into account for health and social care workers, because both the professional groups are essential to palliative, end of life and bereavement care.

Van der Ploeg (2013) identifies in their study needs such as "accommodation," "money," "benefits," "medication management," "incontinence," "memory problems," "inadvertent self-harm," "company," and "daytime activities." Miranda-Castillo et al., (2013) found accommodation, looking after home, food, self-care, mobility, continence, drugs, psychotic symptoms, information, deliberate selfharm, abuse/neglect, behaviour, alcohol, intimate relationships, money, and benefits. Van der Roest et al. (2007) emphasises the daytime activities (understood as any activity that allows persons with dementia to occupy themselves such as social, stimulation, or leisure activities) as the need most unmet. Chung (2006) found that the unmet need that was more evident in his study was the social interaction item of "taking part in activities", and three behavioural items related to memory and emotion, including "repetitive questioning," "restlessness/agitation," and "swings of mood."

Healthcare professionals tend to consider often that the way people indicate their needs is objective. However, this assessment is subjective and depends on previous experiences, expectations, and resources provided to people with dementia to their caregivers. These 83 persons with moderate or severe dementia are known to the integrated continuous care network and receive adequate health and social care related to their condition, but some needs remain unmet. Unmet needs are difficult to define and hard to measure, particularly in people's own homes.

Caring for dependent people with dementia at home is complex due to dementia-related changes including cognitive decline, difficulties in understanding and communication, impaired decision-making, and high levels of comorbidities and mental health issues, and sometimes complex social and spiritual-related circumstances (Tuffrey-Wijne et al., 2016). However, quality home-care services may prevent the deterioration of care needs level when compared with non-home-care services users (Koike \& Furui, 2013). The inadequacies in the needs assessment and management of dementia are associated with higher rates of avoidable hospitalisation and earlier use of long-term care facilities (Phelan, Borson, Grothaus, Balch, \& Larson, 2012; Van der Roest et al., 2009). One important reason is that, at home, it is easier to preserve some small activities, interactions, live in a friendly context, and preserve some memories. This can explain why some care needs in our study show a low number of people who are fully dependent, for example, recognising familiar people, mobility, daytime activities, and asking for social support. Mobility can be easier at home. In other way, hospitalised persons tend to show higher levels of confusion.

Severe frailty and unmet needs can point out a singular opportunity for palliative care interventions to lessen suffering for dementia patients who tend to have low quality of life and high caregiver burden (Hanson et al., 2016; Zalenski et al., 2014).

Van der Steen et al. (2014) highlight that dementia may be prolonged in time and that severe disability can go on for years. The care needs assessment and identifying factors that place people with dementia at risk for frailty may help professionals to tailor interventions to the recipients of care and their caregivers.

\section{1 | Limitations of the study}

The generalisability of the results is subject to certain limitations, typical of such studies, wherever they are carried out. As the identification of needs was articulated with the care delivery and, consequently, more time-consuming to both the person with dementia and his/her family caregiver, it is possible that persons with the most severe dementia or physical disabilities dropped out of the study. Besides that, our study showed that the use of two raters (for data collection and classification) was very complex due to data consuming and the exclusion of the observations for which there was no agreement.

\subsection{Recommendations for further research}

Based on this study, future research should benefit from: (a) using of a larger sample size; (b) assessing specific individual needs and providing continuum-based dementia care to better meet the individual needs of persons with dementia; (c) include in the study spiritual needs as meditators of adjustment, self-confidence, and better interact with a supportive environment. Needs assessment offers an opportunity to more fully understand the experiences of the persons with dementia and their families; one recommendation that makes sense after this study is to choose and use needs assessment tools that opens the communication channel between the recipients of care/family caregivers and the professionals.

\section{5 | CONCLUSION}

This is one of the first studies to provide a detailed examination of the identification of needs of frailty people with moderate to severe 
dementia residing in the family home, with particular reference to functional dependency and IADL. Taking a comprehensive approach to understanding needs arising from such domains in tandem with psychosocial and spiritual needs is an important step towards developing therapeutic and caring strategies to support both the individual and family carers.

Evidence has shown that planning for advanced dementia is often not undertaken (Holmerova et al., 2016; Tolson et al., 2016), due to a lack of consistent information. A comprehensive assessment of the healthcare needs is indispensable to decisions related to the provision of quality care. Conducting a comprehensive healthcare needs assessment can prevent fragmented care and promote comfort and well-being.

The challenge of a comprehensive health care needs assessment cannot be underestimated; when professionals believe that all changes affecting the person are related only to dementia, fundamental health needs can easily be missed (Holmerova et al., 2016). An appropriate care needs assessment can also facilitate the emotional and psychological balance of the caregiver.

\section{CONFLICT OF INTEREST STATEMENT}

The authors report no conflict of interest.

\section{ACKNOWLEDGEMENT}

This research did not receive any specific grant from funding agencies in the public, commercial, or not-for-profit sectors

\section{AUTHORS' CONTRIBUTIONS}

W.A. designed the study, carried out the data collection, designed, and wrote the drafts of the manuscript. H.S. contributed significantly to the statistical analysis. W.A., D.T., G.A.J., N.C., and H.S. contributed to the construction and contents of the manuscript. All authors discussed the results and contributed to the final manuscript.

\section{ORCID}

Wilson Abreu iD http://orcid.org/0000-0002-0847-824X

Debbie Tolson (iD http://orcid.org/0000-0001-9660-5490

\section{REFERENCES}

Abreu, W., Rodrigues, T., Sequeira, C., Pires, R., \& Sanhudo, A. (2017). The experience of psychological distress in family caregivers. Perspectives of Psychiatric Care, 1, 1-22. https://doi.org/10.1111/ppc.12240

Abreu, W., Tolson, D., Jackson, G., \& Costa, N. (2018). A cross sectional study of family caregiver burden and psychological distress linked to frailty and functional dependency of a relative with advanced dementia. Dementia: the International Journal of Social Research and Practice. [Epub ahead of print]. https://doi.org/10.1177/1471301218773842

Aminoff, B. Z. (2014). Prognosis of short survival in patients with advanced dementia as diagnosed by Aminoff suffering syndrome.
American Journal of Alzheimers Disease and Other Dementias, 29(8), 673-677. https://doi.org/10.1177/1533317514539543

Araújo, F., Pais Ribeiro, J., Oliveira, A., Pinto, C., \& Martins, T. (2007). Validation of Lawton and Brody scale in a sample of non-institutionalized elderly [Validação da escala de Lawton e Brody numa amostra de idosos não institucionalizados]. In I. Leal, J. Pais-Ribeiro, I. Silva, $\&$ S. Marques (Eds.), Proceedings of the 7th Congress of Psychology of Health (pp. 217-220). Lisboa, Portugal: ISPA.

Araújo, F., Pais Ribeiro, J., Oliveira, A., Pinto, C., \& Martins, T. (2008). Validação da escala de Lawton e Brody numa amostra de idosos não institucionalizados. I. Leal, J. Pais-Ribeiro, I. Silva, \& S. Marques (Eds.), Actas do $7^{\circ}$ congresso nacional de psicologia da saúde (pp. 217-220). Lisboa, Portugal: ISPA.

Boyle, P., Buchman, A., Wilson, R., Leurgans, S., \& Bennett, D. (2010). Physical frailty is associated with incident mild cognitive impairment in community-based older persons. Journal American Geriatric Sociology, 58, 248-255. https://doi.org/10.1111/j.1532-5415.2009.02671.x

Brewin, C. (2001).Measuring individual needs for care and services. In G. Thornicroft (Ed.), Measuring mental health needs (2nd ed., pp. 283290). London, UK: Gaskell.

Buchman, A., Schneider, J., Leurgans, S., \& Bennett, D. (2008). Physical frailty in older persons is associated with Alzheimer disease pathology. Neurology, 71, 499-504. https://doi.org/10.1212/01.wnl.0000324864.81179.6a

Buchman, A., Yu, L., Wilson, R., Boyle, P., Schneider, J., \& Bennett, D. (2014). Brain pathology contributes to simultaneous change in physical frailty and cognition in old age. The Journals of Gerontology Series A Biological Sciences and Medical Sciences, 69, 1536-1544. https://doi. org/10.1093/gerona/glu117

Burla, C., Rego, G., \& Nunes, R. (2014). Alzheimer, dementia and the living will: A proposal. Medicine Health Care and Philosophy, 17(3), 389-395. https://doi.org/10.1007/s11019-014-9559-8

Callahan, C.-M., Boustani, M. A., Unverzagt, F. W., Austrom, M. G., Damush, T. M., Perkins, A. J., ... Hendrie, H. C. (2006). Effectiveness of collaborative care for older adults with Alzheimer disease in primary care: a randomized controlled trial. JAMA, 295(18), 2148-2157. https://doi.org/10.1001/jama.295.18.2148.

Cavanagh, S., \& Chadwick, K. (2005). Health needs assessment: A practical guide [Internet]. [cited 2017 Sept 09]. Available from https:// www.k4health.org/sites/default/files/migrated_toolkit_files/ Health_Needs_Assessment_A_Practical_Guide.pdf

Chung, J. (2006). Care needs assessment of older Chinese individuals with dementia of Hong Kong. Aging \& Mental Health, 10(6), 631-637. https://doi.org/10.1080/13607860600650532

Clegg, A., Young, J., lliffe, S., Rikkert, M., \& Rockwood, K. (2016). Frailty in elderly people. The Lancet, 381(9868), 752-762. https://doi. org/10.1016/S0140-6736(12)62167-9

Crowther, G. (2015). Palliative care in dementia. London, UK: Radcliffe Publishing.

Dhedhi, S., Swinglehurst, D., \& Russell, J. (2014). Timely diagnosis of dementia: What does it mean? A narrative analysis of GPs' accounts. British Medical Journal Open, 4(3), e004439. https://doi.org/10.1136/ bmjopen-2013-004439

Dinand, C., Nover, S., Holle, D., Zischka, M., \& Halek, M. (2016). What is known about the subjective needs of people with behavioural variant frontotemporal dementia? A scoping review. Health and Social Care in the Community, 24(4), 375-385. https://doi.org/10.1111/hsc.12225

Fried, L., Tangen, C., Walston, J., Newman, A., Hirsch, C., Gottdiener, J., ... McBurnie, M. (2001). Frailty in older adults: Evidence for a phenotype. The Journals of Gerontology Series A Biological Sciences and Medical Sciences, 56, M146-M156. PMID: 11253156. https://doi. org/10.1093/gerona/56.3.M146

Garret, C., Santos, F., Tracana, I., Barreto, J., Sobral, M., \& Fonseca, R. (2008). Clinical evaluation of dementia. Scales and tests in dementia [Avaliação clínica da demência. Escalas e testes na demência] Grupo de Estudos de Envelhecimento Cerebral e Demências. 
Gray, S., Anderson, M., Hubbard, R., LaCroix, A., Crane, P., McCormick, W., ... Larson, E. (2013). Frailty and incident dementia. The Journals of Gerontology Series A Biological Sciences and Medical Sciences, 68(9), 1083-1090. https://doi.org/10.1093/gerona/glt013

Hanson, E., Hellstrom, A., Sandvide, A., Jackson, G. A., MacRae, R., Waugh, A., ... Tolson, D. (2016). The extended palliative phase of dementia - An integrative literature review. Dementia, 1-27, https://doi. org/10.1177/1471301216659797

Heuberger, R. (2011). The frailty syndrome: A comprehensive review. Journal of Nutrition in Gerontology and Geriatrics, 30, 315-368. https://doi.org/10.1080/21551197.2011.623931

Holmerová, I., Waugh, A., MacRae, R., Veprková, R., Sandvide, A., Hanson, E., ... Tolson, D. (2016). Best Practice Statement (Manual). Project: Dementia Palliare: Interprofessional experiential learning solutions: Equipping the qualified dementia workforce to champion evidence informed improvement to advanced dementia care and family caring project. EU, Erasmus Plus, Palliare Project.

Hughes, C., Berg, L., Danziger, W., Coben, L., \& Martin, R. (1982). A new clinical scale for the staging of dementia. British Journal of Psychiatry, 140, 566-572. https://doi.org/10.1192/bjp.140.6.566

Johansson, G., Eklund, K., \& Gosman-Hedstrom, G. (2010). Multidisciplinary team, working with elderly persons living in the community: a systematic literature review. Scandinavian Journal of Occupational Therapy, 17(2), 101-116. https://doi. org/10.3109/11038120902978096

Jones, L., Candy, B., Davis, S., Elliott, M., Gola, A., Harrington, J., ... Sampson, E. L. (2016). Development of a model for integrated care at the end of life in advanced dementia: A whole systems UK-wide approach. Palliative Medicine, 30(3), 279-295. https://doi. org/10.1177/0269216315605447

Kalyani, R., Varadhan, R., Weiss, C., Fried, L., \& Cappola, A. (2012). Frailty status and altered glucose-insulin dynamics. The Journals of Gerontology Series A: Biological Sciences and Medical Sciences, 67, 1300-1306. https://doi.org/10.1093/gerona/glr141

Koike, S., \& Furui, Y. (2013). Long-term care-service use and increases in care-need level among home-based elderly people in a Japanese urban area. Health Policy, 110, 94-100. https://doi.org/10.1016/j. healthpol.2012.12.011

Lawton, M., \& Brody, E. (1969). Assessment of older people: self-maintaining and instrumental activities of daily living. Gerontologist, 9(3), 179-186.

Mahoney, F., \& Barthel, D. (1965). Functional evaluation: The Barthel Index. Maryland State Medical Journal, 14, 56-61. https://doi. org/10.1177/0269216315605447

Martins, D., Carvalho, I., Cordeiro, N., \& Pinheira, V. (2012). Contribution to the validation of the Edmonton Fragility Scale (EFS) for the Portuguese reality (Contributo para a validação da Escala de Fragilidade de Edmonton (EFS) para a realidade portuguesa). Castelo Branco, Portugal: International Portuguese-Spanish Congress.

McWalter, G. J., Toner, H. L., Corser,A. S., Eastwood, J., Marshall, M. T., \& Turvey, T. (1994). Needs and needs assessment: their components and definitions with reference to dementia. Health Social Care Community, 2 (4), 213-219. https://doi.org/10.1111j.1365-2524.1994.tb00167.x

McWalter, G. J., Toner, H., McWalter, A., Eastwood, J., Marshall, M., \& Turvey, T. (1998). A Community needs assessment: For care needs assessment pack for dementia (CARENAPD) - It's development, reliability and validity. International Journal of Geriatric Psychiatry, 13, 16-22. https://doi.org/10.1002/(sici)1099-1166(199801)13:1 $<16:$ :aid-gps721>3.0.co;2-n

Meaney, A. M., Croke, M., \& Kirby, M. (2005). Needs assessment in dementia. International Journal of Geriatric Psychiatry, 20(4), 322-329. https://doi.org/10.1002/gps.1284

Miranda-Castillo, C., Woods, B., Galboda, K., Oomman, S., Olojugba, C., \& Orrell, M. (2010). Unmet needs, quality of life and support networks of people with dementia living at home. Health and Quality of Life Outcomes, 8(1), 132. https://doi.org/10.1186/1477-7525-8-132

Miranda-Castillo, C., Woods, B., \& Orrell, M. (2013). The needs of people with dementia living at home from user, caregiver and professional perspectives: a cross-sectional survey. BMC Health Services Research, 13, 43. https://doi.org/10.1186/1472-6963-13-43

Muders, P., Zahrt-Omar, C., Bussmann, S., Haberstroh, J., \& Weber, M. (2015). Support for families of patients dying with dementia: A qualitative analysis of bereaved family members' experiences and suggestions. Palliative Support Care, 13, 435-442. https://doi.org/10.1017/ S1478951513001107

Nunes, B., Silva, R., Cruz, V., Roriz, J., Pais, J., \& Silva, M. (2010). Prevalence and pattern of cognitive impairment in rural and urban populations from Northern Portugal. BMC Neurology, 10(1). 42. https://doi.org/10.1186/1471-2377-10-42

Phelan, E., Borson, S., Grothaus, L., Balch, S., \& Larson, E. B. (2012). Association of incident dementia with hospitalizations. JAMA, 307(2), 165. https://doi.org/10.1001/jama.2011.1964

Pialoux, T., Goyard, J., \& Lesourd, B. (2012). Screening tools for frailty in primary health care: A systematic review. Geriatrics \& Gerontology International, 12), 189-197. https://doi. org/10.1111/j.1447-0594.2011.00797.x

Pimlott, N., Persaud, M., Drummond, N., Cohen, C., Silvius, J., Seigel, K., ... Dalziel, W. B. (2009). Family physicians and dementia in Canada. Part 2. Understanding the challenges of dementia care. Canadian Family Physician, 55, 508-509.e1-7. Available from www.cfp.ca/content/55/5/508.full.pdf+html

Potter, J. M., Fernando, R., \& Humpel, N. (2013). Development and evaluation of the REACH (recognise end of life and care holistically) out in dementia toolkit. Australasian Journal on Ageing, 32(4), 241-246. https://doi.org/10.1111/ajag.12062

Prince, M., Wimo, A., Guerchet, M., Ali, G., Wu, Y., \& Prina, M. (2015). World Alzheimer Report 2015: The global impact of dementia. An analysis of prevalence, incidence, costs and trends. London, England: Alzheimer's Disease International.

Raji, M., Snih, S., Ostir, G., Markides, K., \& Ottenbacher, K. (2010). Cognitive status and future risk of frailty in older Mexican Americans. The Journals of Gerontology Series A Biological Sciences and Medical Sciences, 65, 1228-1234. https://doi.org/10.1093/ gerona/glq121

Rodríguez-Mañas, L., Féart, C., Mann, G., Viña, J., Chatterji, S., ChodzkoZajko, W., ... Vega, E. (2012). Searching for an operational definition of frailty: A Delphi method based consensus statement. The frailty operative defnition-consensus conference project. The Journals of Gerontology Series A Biological Sciences and Medical Sciences, 68, 6267. https://doi.org/10.1093/gerona/gls119

Rolfson, D., Majumdar, S., Tsuyuki, R., Tahir, A., \& Rockwood, K. (2006). Validity and reliability of the Edmonton Frail Scale. Age and Ageing, 35, 526-529. PMID: 16757522. https://doi.org/10.1093/ageing/ afl041

Sampson, E. L. (2010). Palliative care for people with dementia. British Medical Bulletin, 96, 159-174. https://doi.org/10.1093/bmb/ldq024

Scholzel-Dorenbos, C., Meeuwsen, E., \& Rikkert, M. (2010). Integrating unmet needs into dementia health-related quality of life research and care: Introduction of the Hierarchy Model of Needs in Dementia. Aging \& Mental Health, 14(1), 113-119. https://doi. org/10.1080/13607860903046495

Sheeman, B. (2012). Assessment scales in dementia. Therapeutic Advances in Neurological Disorders, 5(6), 349-358. https://doi. org/10.1177/1756285612455733

Tolson, D., Fleming, A., Hanson, E., Abreu, W., Lillo Crespo, M., Macrae, R., ... Holmerova, I. (2016). Achieving prudent dementia care (Palliare): An international policy and practice imperative. International Journal of Integrated Care, 16(4), 1-11. https://doi.org/10.5334/ijic.2497 
Tolson, D., Holmerova, I., Macrae, R., Waugh, A., Hvalič-Touzery, S., de Abreu, W., ... Hanson, E. (2017). Improving advanced dementia care: An interprofessional palliare learning framework, Journal of the American Medical Directors Association, 18, 561-563. https://doi. org/10.1016/j.jamda.2017.03.014

Tuffrey-Wijne, I., Wicki, W., Heslop, P., McCarron, M., Todd, S., Oliver, D., ... Curfs, L. (2016). Developing research priorities for palliative care of people with intellectual disabilities in Europe: A consultation process using nominal group technique. BMC Palliative Care, 15, 36. https://doi.org/10.1186/s12904-016-0108-5

Van der Steen, J., Radbruch, L., Hertogh, C., de Boer, M., Hughes, J., Larkin, P., ... Volicer, L. (2014). White paper defining optimal palliative care in older people with dementia: A Delphi study and recommendations from the European Association for Palliative Care. Palliative Medicine, 28(3), 197-209. https://doi.org/10.1177/0269216313493685

Van derPloeg, E. S., Bax, D., Boorsma, M., Nijpels, G., \& VanHout, H. P. (2013). A cross-sectional study to compare care needs of individuals with and without dementia in residential homes in the Netherlands. BMC Geriatrics, 13, 1-8. https://doi.org/10.1186/1471-2318-13-51

Van der Roest, H., Meiland, F., Comijs, H., Derksen, E., Jansen, A., VanHout, H., ... Dröes, R. (2009). What do community-dwelling people with dementia need? A survey of those who are known to care and welfare services. International Psychogeriatrics, 21, 949-965. https://doi.org/10.1017/S1041610209990147

Van der Roest, H., Meiland, F., Maroccini, R., Comjis, H., Jonker, C., \& Dröes, R. (2007). Subjective needs of people with dementia: A review of the literature. International Psychogeriatrics, 19(03), 559-592. https://doi.org/10.1017/S1041610206004716

Walston, J., Hadley, E., Ferrucci, L., Guralnik, J., Newman, A., Studenski, S., ... Fried, L. (2006). Research agenda for frailty in older adults: Toward a better understanding of physiology and etiology:
Summary from the American Geriatrics Society/National Institute on Aging Research Conference on Frailty in Older Adults. Journal of the American Geriatrics Society, 54(6), 991-1001. https://doi. org/10.1111/j.1532-5415.2006.00745.x

Winblad, B., Amouyel, P., Andrieu, S., Ballard, C., Brayne, C., Brodaty, H., ... Zetterberg, H. (2016). Defeating Alzheimer's disease and other dementias: A priority for European science and society. The Lancet Neurology, 15(5), 455-532. https://doi.org/10.1016/ S1474-4422(16)00062-4

World Health Organization (2015). The epidemiology and impact of dementia current state and future trends. Geneve, Switzerland: WHO.

Wou, F., \& Conroy, S. (2013). The frailty syndrome. Medicine, 41, 13-15. https://doi.org/10.1016/j.mpmed.2012.10.004

Zalenski, R., Courage, C., Edelen, A., Waselewsky, D., Krayem, H., Latozas, J., \& Kaufman, D. (2014). Evaluation of screening criteria for palliative care consultation in the MICU: A multihospital analysis. BMJ Supportive \& Palliative Care, 1-9. https://doi.org/10.1136/ bmjspcare-2013-000570

How to cite this article: Abreu W, Tolson D, Jackson GA, Staines $\mathrm{H}$, Costa $\mathrm{N}$. The relationship between frailty, functional dependence, and healthcare needs among communitydwelling people with moderate to severe dementia. Health Soc Care Community. 2019;27:642-653. https://doi.org/10.1111/ hsc. 12678 